\title{
Augmentation of Mast Cell Stability, a Therapeutic Strategy for Idiopathic Pulmonary Fibrosis
}

\author{
S. M. ABDULLAH AND *P. M. MAZUMDER \\ Department of Pharmaceutical Sciences and Technology, Birla Institute of Technology, Mesra-835215, Ranchi, Jharkhand, \\ India
}

Abdullah and Mazumder: Therapeutic Strategies for Idiopathic Pulmonary Fibrosis

\begin{abstract}
Idiopathic pulmonary fibrosis is a continuous deteriorating type of interstitial lung disease. In clinical practice, inhibition of fibrotic progression is essential. Currently available interventions for idiopathic pulmonary fibrosis are confined to prophylactic effects and also have limitations with dose-associated adverse effects. Progressive nature of idiopathic pulmonary fibrosis and unavailability of therapeutic drugs together is a huge setback for treating advanced stages of fibrotic conditions. Further, monotherapy with antifibrotic agents may not be adequate as various underlying mechanisms are involved in the development of idiopathic pulmonary fibrosis. The present article made an attempt to discuss potential targets that could impede fibrotic progression for developing mechanism-based strategies for the therapeutic control of idiopathic pulmonary fibrosis. A suitable combination therapy to potentiate antifibrotic effects with parallel augmentation of mast cell stability could be considered as a possible approach to stop disease progression as well as aid in the reversal of fibrotic condition in established idiopathic pulmonary fibrosis.
\end{abstract}

Key words: Antifibrotic agents, combination therapy, idiopathic pulmonary fibrosis, mast cell stability

Idiopathic pulmonary fibrosis (IPF) is a frequent type of interstitial lung disease, coupled with progressive tissue damage. It has unidentified etiology and imprecise pathogenesis. However, it is characterized by chronic inflammation and excess accumulation of extracellular matrix (ECM) components in lungs ${ }^{[1]}$. Globally, the incidence of IPF is found to be equivalent to stomach, liver, testicular and cervical cancer ${ }^{[2]}$. Prognosis of IPF is reported to be very poor with consistent progression of the disease ${ }^{[3,4]}$. The life expectancy in IPF is restricted to almost $3 \mathrm{y}$ as median survival with $50 \%$ mortality after its confirmed diagnosis ${ }^{[4,5]}$.

In the last few decades, considerable research efforts were applied to develop an effective antifibrotic agent. Unfortunately, despite various attempts except two drugs, pirfenidone and nintedanib, no other drug was approved by USFDA for the treatment of $\mathrm{IPF}^{[4]}$. The effects of these drugs are limited to slowing down the disease progression but not reversal of fibrotic severity in established $\mathrm{IPF}^{[6]}$. Recent clinical data on drugs revealed that these have dose-related adverse effects ${ }^{[3]}$. Moreover, pre-clinical studies indicated carcinogenic potential ${ }^{[7]}$. In the CAPACITY trial, the nintedanib-

*Address for correspondence E-mail: pmitramazumder@bitmesra.ac.in

March-April 2020 administered group reported diarrhea in $>90 \%$ of patients as the major adverse effect and also elevated levels of hepatic enzymes were $\operatorname{seen}^{[8]}$. Therapeutically safe and effective drug therapy is the ultimate requirement in the management of IPF. Sub-therapeutic action and associated adverse effects of conventional interventions usually impel the clinicians to look for the alternative treatments.

This review is an attempt to contribute to the knowledge of potential targets to impede disease progression and possible combination therapy to overcome the limitations of antifibrotic agents against IPF. In this article, an overview of the pathogenesis of IPF has been represented and subsequently the role of mast cells in the development of IPF has been discussed. Also, previous studies outcome of newly recognized antifibrotic agents have been summarized. Further,

This is an open access article distributed under the terms of the Creative Commons Attribution-NonCommercial-ShareAlike 3.0 License, which allows others to remix, tweak, and build upon the work non-commercially, as long as the author is credited and the new creations are licensed under the identical terms

Accepted 23 February 2020

Revised 14 February 2020

Received 14 November 2019

Indian J Pharm Sci 2020;82(2):193-202 
various mechanisms of antifibrotic agents involved in mast cell stabilization has been portrayed, which has been considered for the advancement of therapeutic control in IPF.

The data extracted included clinical, pre-clinical, systematic reviews and clinical practice guidelines published in PubMed and Google Scholar database using the keywords, idiopathic pulmonary fibrosis, mast cell, chronic inflammation and antifibrotic agents. Literature review included articles published during 1990 to 2019, which were used for the preparation of this manuscript. However, some relevant references from much older publications have also been included.

\section{PATHOGENESIS OF IDIOPATHIC PULMONARY FIBROSIS}

The actual reasons behind the onset of IPF are unknown and pathogenesis is also not clear. Broadly it has been suggested, that, IPF develops usually by repeated occurrence of microinjury to alveolar epithelial cells $(\mathrm{AECs})^{[6,9]}$. It is essential to understand the cellular and molecular interactions in the development of IPF, mainly to derive effective therapeutic strategies. In general, fibrosis involves complicated inflammatory process, which occurs in association with several inflammatory mediators. During microinjury to AEC, inflammatory cells release various inflammatory mediators that can participate either to stimulate (profibrotic) or to inhibit (antifibrotic) the development of fibrosis. As per integrated views of several researches, chronic inflammation and disturbances in tissue healing process due to frequent microinjuries are the main concerns in the pathogenesis of $\operatorname{IPF}^{[1,9]}$, where fibrosis may be developed under the influence of profibrotic mediators secreted from inflammatory cells ${ }^{[1,6]}$. Overall, it has been suggested that most important pathological factor responsible for onset of IPF is chronic inflammation ${ }^{[10]}$.

Inflammation and fibrosis are interrelated with complicated signaling mechanisms ${ }^{[11]}$. Immediately after the incidence of microinjury, tissue repairing process initiate various types of cell interaction in which, the involvements of inflammatory cells are consider as the critical step ${ }^{[1]}$. Generally, microinjury to AECs and their subsequent response are associated directly to oxidative stress and inflammation. Persistent exposure of stimuli creates oxidative stress that leads to tissue damage, however, inflammation as a natural protective defense mechanism responses against the tissue injury ${ }^{[1]}$, where mast cells play a chief function to initiate the process of inflammation ${ }^{[12,13]}$ by releasing

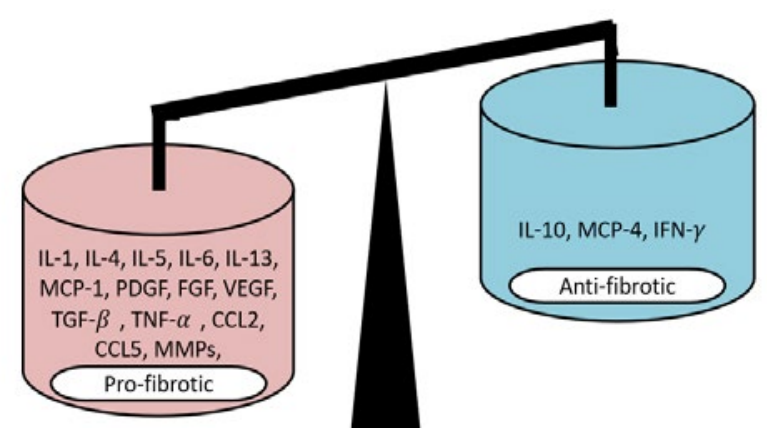

Fig. 1: Mast cell Inflammatory mediators involved profibrotic and antifibrotic effects ${ }^{[45,81-83]}$

CCL- chemokine ligand; FGF- fibroblast growth factor; IFNinterferon; IL- interleukin; MCP- monocyte chemoattractant protein; MMPs- matrix metalloproteinases; PDGF- plateletderived growth factor; TNF- tumor necrosis factor; TGF- tumor growth factor; VEGF- vascular endothelial growth factor.

various inflammatory mediators as shown in fig. 1 .

Inflammatory mediator release by mast cells can also occur as a consequence of other well-known factor such as allergens. Mast cell degranulation in allergic reactions involves FceRI receptor activation. This receptor is vastly expressed on the surface of mast cells and correspondingly governed by increased concentrations of $\operatorname{IgE}^{[14]}$. The increased concentration of $\operatorname{IgE}$ in serum has been found to accompany pulmonary fibrosis ${ }^{[15]}$. Repeated degranulation of mast cells create imbalance between profibrotic and antifibrotic mediators, which finally provokes intense fibroblast activity and the activated fibroblast primarily participates in the pathogenesis of pulmonary fibrosis ${ }^{[16]}$. Moreover, epithelia mesenchymal transition, fibroblast differentiation into myofibroblast, over production of collagen, excess ECM deposition and subsequent cellular structural remodeling arises as characteristic of $\mathrm{IPF}^{[9,10]}$.

\section{ROLE OF MAST CELLS IN IDIOPATHIC PULMONARY FIBROSIS}

Agents targeting the inflammatory cells like lymphocytes, macrophages and neutrophils could not inhibit the development of fibrosis. However, in the fibrotic condition it is reported that, concentration of mast cell increases and promotes fibrosis by the release of histamine, renin and growth factors ${ }^{[17]}$. Recently, histamine and renin have been identified as two fibrotic mediators primarily released from mast cells, which promote proliferation, Transforming growth factor- $\beta$ (TGF- $\beta$ ) secretion and collagen synthesis by activating the fibroblasts in lungs of both human as well as rats ${ }^{[18]}$. Mast cell as the chief effector cell in inflammatory disease such as interstitial lung disease (ILD), is widely 
expected to be accountable for the initiation of organ fibrosis $^{[19]}$, where, specifically Th2 cytokine (IL-9) initiates the mast cell recruitment and activation ${ }^{[20]}$. Chronic inflammation that occurs due to repeated lung injury causes frequent mast cell activation and recruitment in particular organ, which in turn leads to initiate fibroblast proliferation, differentiation and excess collagen production and ultimately assist in fibrotic disease progression ${ }^{[21]}$. Further, inflammatory damage can develop fibroblastic foci by continuous activity of TGF- $\beta$, platelet-derived growth factor (PDGF) and the basic fibroblast growth factor (bFGF) ${ }^{[22]}$. Chymase is the protease enzyme, primarily released from the mast cell, increases TGF- $\beta$ activity and promotes establishment of pulmonary fibrosis ${ }^{[23]}$ by activating fibroblast proliferation, excess production of collagen and matrix metalloproteinases (MMPs) ${ }^{[24]}$. Post allergen challenge, chymase may also participate in development of sub-epithelial fibrosis ${ }^{[25]}$. Among various mast cell mediators, chymase is considered as the main component responsible for the transformation of TGF- $\beta$ from latent to active form ${ }^{[26]}$ whereby, TGF- $\beta$ play a key role in fibroblast activation, proliferation and fibroblast-myofibroblast differentiation ${ }^{[27]}$. Tryptase, is another protease enzyme, which is expressed by all kinds of mast cells and contributes to inflammation in many types of autoimmune diseases as well as in fibrosis ${ }^{[28,29]}$. Trans-differentiation of fibroblast into myofibroblast has a critical concern in the development of IPF related to overexpression of tumor necrosis factor $\alpha($ TNF- $\alpha)$ and excess deposition of ECM that provides rigidity to the cells structure ${ }^{[30]}$. In addition, mast cells synthesize and store proteoglycans likes chondroitin sulphate and hyaluronic acid ${ }^{[31]}$, which are released as matrix components in the lung interstitial space post degranulation and cause cellular structural remodeling either directly or by mitogenic effects on lung fibrotic cells ${ }^{[32]}$.

In vivo study conducted in mice has showed that protease enzymes released from mast cells have direct contribution in bleomycin-induced interstitial lung injury ${ }^{[33]}$. Further, a comparative clinical study between fibrotic and non-fibrotic lungs, has demonstrated severity of fibrotic conditions had been increased with the increase in number of mast cells ${ }^{[34]}$. Additionally in IPF patients, the histamine level in bronchoalveolar fluid (BALF) has been reported 10 times higher in comparison to control individuals ${ }^{[35]}$, which is also associated with elevated levels of tryptase and mast cells are considered the major source of both histamine and tryptase ${ }^{[36]}$. Furthermore, it has been reported that, human lung mast cell releases tryptase enzyme upon activation by co-culturing with lung fibroblasts obtained from IPF patients ${ }^{[36]}$ and the presence of excess of inflammatory cells in the lungs tissue indicates continuous process of mast cell degranulation ${ }^{[34]}$. Moreover in IPF patients, infiltrations of inflammatory cells represented that, release of growth factors mainly TGF- $\beta$, is responsible for the onset of fibrosis ${ }^{[37]}$, by deposition of collagen fibers, smooth muscle cells (SMC), fibroblasts and myofibroblast type cells ${ }^{[36,37]}$. In case of diffuse interstitial fibrotic patients, increased secretion of stem cell factor (SCF) from lung fibroblasts has been reported, which may also has an important contribution in the establishment of $\operatorname{ILD}^{[38]}$. Furthermore, in comparison to control subjects, the expression of SCF was found elevated in intact lung tissue as well as in isolated lung fibroblasts from IPF patients ${ }^{[36]}$. These interpretations advocate that interaction between mast cells and fibroblasts play a pivotal role in excess deposition of ECM and lead to develop lung fibrosis. Moreover, a previous study demonstrated, upon activation, mast cells release many of the profibrotic mediators locally that include chymase, tryptase, renin, histamine, leukotriene and TGF- $\beta^{[39]}$. Hence, it appears clearly that mast cells are closely associated with fibrosis ${ }^{[36,40]}$, where in, mast cell-derived TGF- $\beta$ promotes fibroblast activation, proliferation and differentiation into myofibroblasts ${ }^{[41]}$ and play a critical role in the development of pulmonary fibrosis as illustrated in fig. 2.

\section{TARGETS TO IMPEDE FIBROTIC PRO- GRESSION}

Mast cells are involved in immune reactions, usually facilitate allergic diseases such as anaphylaxis, allergic rhinitis and asthma ${ }^{[13,42]}$, as well as inflammatory diseases such as chronic obstructive pulmonary disorder and ILD $^{[21]}$. Mast cells commonly become activated through conjugation of IgE with FceRI receptors, which are present in excess on the mast cell surface ${ }^{[43]}$. Activation of mast cell can also occur by means of cytokines and other micro-environmental stimuli ${ }^{[44]}$. Generally, mast cells release various kinds of vasoactive and inflammatory mediators stored in granules within cytoplasm after receiving activation threshold ${ }^{[45]}$ where, intracellular calcium ion concentration plays a significant role in the degranulation process ${ }^{[46]}$. Also, control of actin cytoskeleton mechanics to be considered as a decisive step in preventing the mast cell degranulation ${ }^{[47]}$ primarily depends on intracellular calcium ion concentration as shown in fig. 3 . 


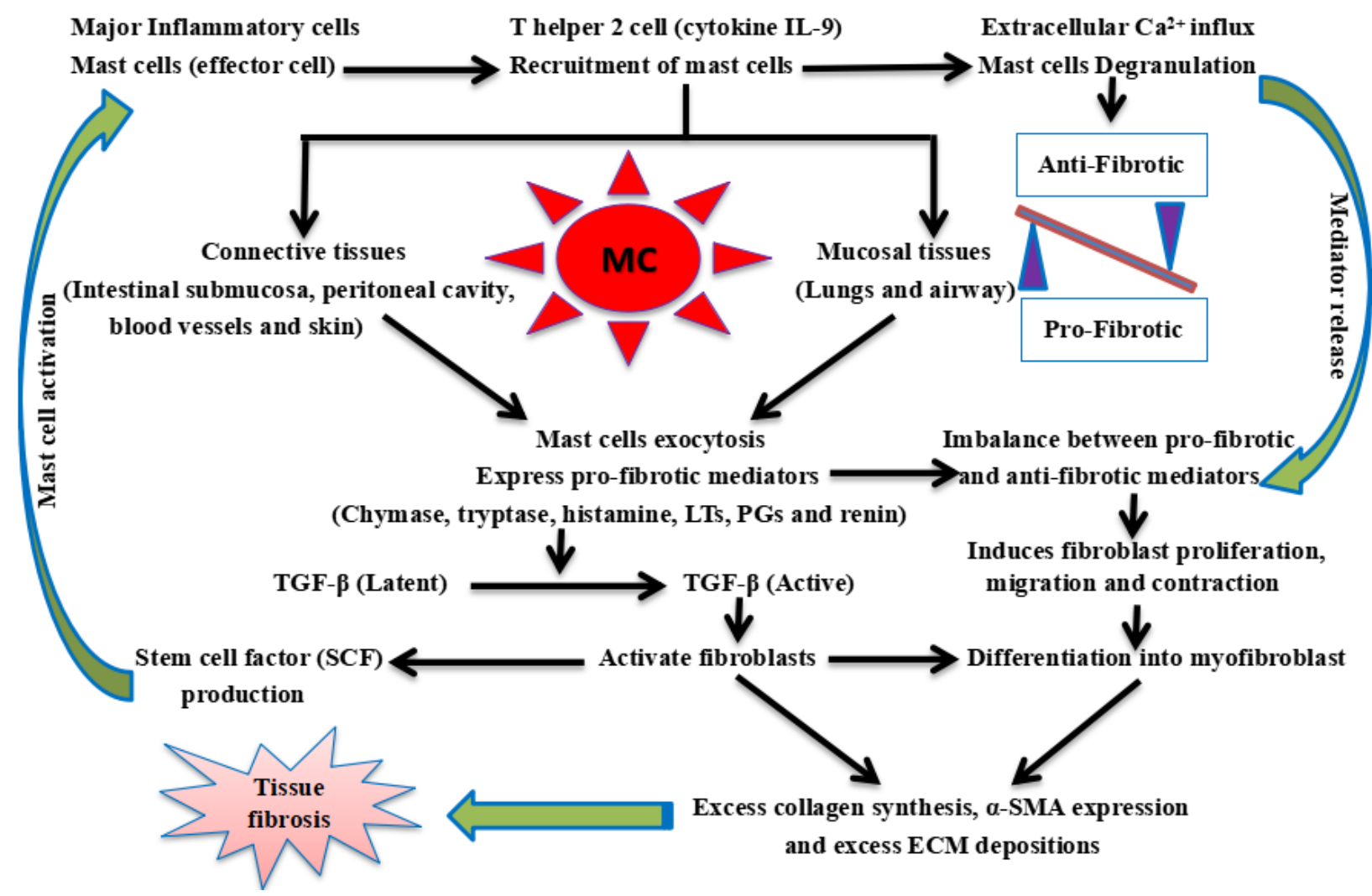

Fig. 2: Involvement of mast cells in activation, proliferation and differentiation of fibroblasts by means of various profibrotic mediators release after degranulation process that ultimately leads to development of tissue fibrosis

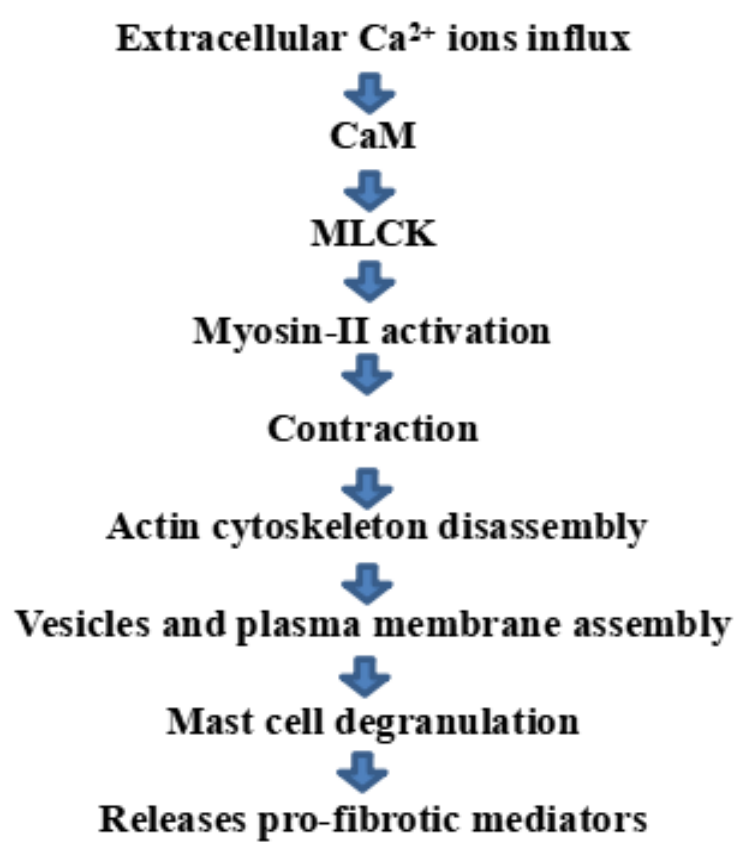

Fig. 3: Flow diagram of sequential steps involved in the mast cell degranulation

Sequential steps involved in the mast cell degranulation initiated by extracellular $\mathrm{Ca}^{2+}$ ions influx that finally leads to liberation of profibrotic mediators
Chronic inflammation as an important underlying mechanism of $\mathrm{IPF}^{[10]}$, mast cell degranulation materializes frequently and creates imbalance between profibrotic and antifibrotic mediators ${ }^{[16]}$. These conditions lead to continuous disturbance in homeostasis ${ }^{[44]}$. In chronic inflammatory condition, degranulation of mast cells may take place in uncontrolled manner and releases excess of profibrotic mediators (cytokines, chemokines, growth factors and proteases) within target organ as represented in fig. 1, which provoke downstream mechanisms leading to progressive fibrosis ${ }^{[48]}$ by involving different signaling pathways mainly PPAR- $\gamma$, NF-kB and TGF- $\beta /$ Smad $^{[49]}$. Thus, controlling excessive mast cell degranulation would provide potential therapeutic value in inhibition of fibrosis progression.

In view to inhibit mast cell degranulation, stabilizing agents can be used to prevent the activation of mast cell, where, it acts one step before the initiation of inflammatory cascade. But, the entire blockade of degranulation process practically might not be possible by using single mechanism based mast cell stabilizing 
agent. Since, the major factor involved in mast cell degranulation process is usually intracellular calcium ion concentration, which is governed by various mechanisms as represented in fig. 4 .

Targeting more than one mechanism to inhibit either direct or indirect entry of extracellular calcium ion would be wise enough and might produce profound inhibition of profibrotic mediator release by augmenting mast cell stability. Similarly, to get more control on the progression of IPF, optimum inhibition of mast cell degranulation is needed. This could be achievable by considering suitable combination of drugs acting by different mechanisms as potential tools to impede IPF progression.

\section{ANTIFIBROTIC AGENTS WITH MAST CELL STABILIZATION PROPERTIES}

Essentially, based on the outcome of recent pre-clinical studies, some active agents have been recognized that have preventive potential against animal models of
IPF along with interesting facts related to ability to alter mast cell degranulation via different mechanisms. These antifibrotic agents included adenylyl cyclase activators, $\beta$-adenoreceptor agonists, flavonoids, mast cell stabilizers, phosphodiesterase inhibitors and procyanidins $^{[50-69]}$. The antifibrotic actions of these agents have been reported at initial and pre-clinical stages as discussed below. However, their individual contributions in stabilizing the mast cell via different mechanisms are represented in fig. 4.

\section{Adenylyl cyclase activators:}

Forskolin, a diterpene from the roots of Coleus forskohlii, causes direct activation of adenylyl cyclase $^{[50]}$. In a previous study, it had been observed that adenylate cyclase activity increased by 10 -fold in rat cerebral cortical membranes after administration of forskolin. Activation of adenylyl cyclase enzyme leads to increase in the formation of cAMP. Forskolin mimics the effects of $\beta$-adrenoceptor agonists on fibroblast

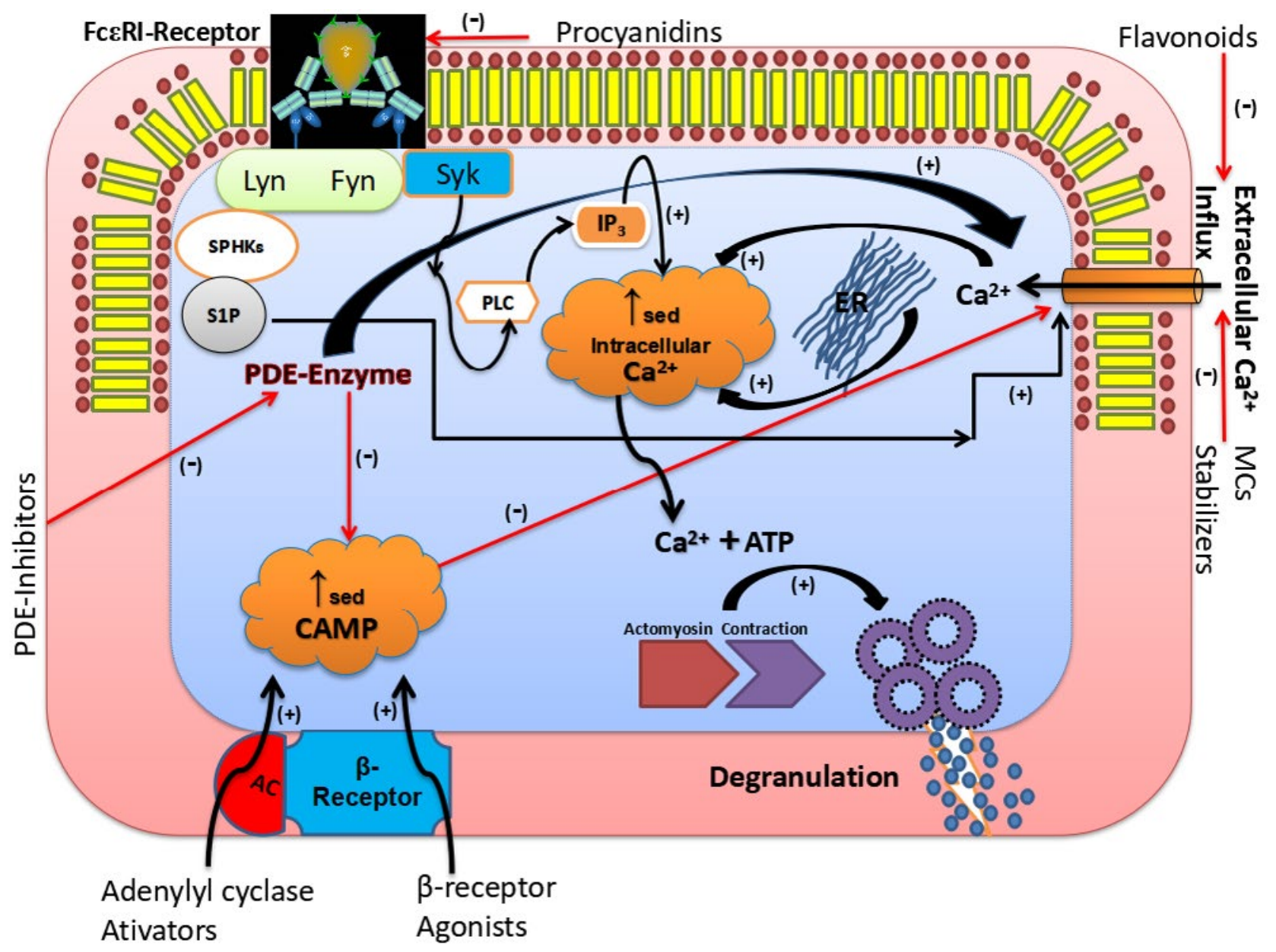

Fig. 4: Various mechanism of antifibrotic agents

Mechanisms of adenylyl cyclase activators, $\beta$-receptor agonists, flavonoids, mast cell stabilizers, phosphodiesterase inhibitors and Procyanidins involved in inhibition of mast cell degranulation acts through different specific targets including receptors, ions channels and enzymes and their favours in stabilization of mast cell. $(+)$ promoting effect; $(-)$ preventing effect 
activation and proliferation. It also exhibited inhibitory effects on collagen synthesis, but diminished inhibition of fibroblast activity in fibrotic lungs due to insufficient phosphorylation of cAMP-response element binding (CREB) protein ${ }^{[51]}$. The role of cAMP in association with TGF- $\beta$ had been investigated in the development of $\mathrm{IPF}^{[52]}$. Activation of cAMP exhibited reduction of myofibroblasts formation and deposition of $\mathrm{ECM}^{[53]}$. Therefore, agents such as forskolin that increase cAMP could be beneficial in mitigating IPF disease progression.

\section{$\beta$-Adrenoceptors agonists:}

$\beta$-adrenoceptor agonists inhibit many functions of lung fibroblasts. Non selective $\beta$-adrenoceptor agonist, isoprenaline as well as long-acting $\beta 2$-adrenoceptor agonist formoterol and salmeterol inhibit cultured human lungs fibroblast proliferation. Isoprenaline, formoterol and salmeterol down regulated collagen synthesis ${ }^{[54-56]}$. Additionally, formoterol or salmeterol inhibited various cytokines including interleukin-1 $\beta$ (IL-1 $\beta$ ), TNF- $\alpha$ or induced interferon- $\gamma(\mathrm{IF}-\gamma)$ expression ${ }^{[57,58]}$. Salmeterol decreased the basal and TNF- $\alpha$ related expression of $\alpha$-smooth muscle actin ( $\alpha$-SMA) protein and fibroblastmyofibroblast differentiation ${ }^{[58]}$.

\section{Flavonoids:}

There are different types of flavonoids, quercetin, luteolin and chrysin which were studied against bleomycin-induced pulmonary fibrosis in rodents. Effects of quercetin in bleomycin-induced pulmonary fibrosis revealed that bleomycin increased levels of BALF protein, hydroxyproline, malondialdehyde and total antioxidative capability of the lung tissue and the decreased levels of GSH/GSSG were almost reversed after treatment for $24 \mathrm{~d}^{[59]}$. Moreover, an in vitro study showed that quercetin could reverse the resistance to apoptosis of fibroblasts and modified the progression of firm pulmonary fibrosis in aged mice ${ }^{[60]}$.

Similarly, chrysin exhibited protective effects on cell injury in lung fibrosis induced by bleomycin in rats. It was reported that chrysin has potential to significantly inhibit the bleomycin-induced lungs inflammation and fibrosis and also to reduce the activities of CAT, SOD, and levels of $\mathrm{GSH}^{[61]}$.

Oral administration of luteolin (10 mg/kg) efficiently suppressed neutrophil infiltration, including elevated TNF- $\alpha$ and IL-6 levels in BALF, post bleomycin instillation in $\mathrm{C} 57 \mathrm{BL} / 6 \mathrm{~J}$ mice. Luteolin demonstrated the ability to alleviate collagen deposition, TGF- $\beta 1$ expression and lung fibrosis. However, these effects are mediated by inhibition of lungs inflammation and suppression of myofibroblast differentiation as well as epithelial mesenchymal cell transition ${ }^{[62]}$.

\section{Mast cell stabilizers:}

In an experimental study to understand the contribution of mast cells in initiating pulmonary fibrosis, mast celldeficient (MCD) mice were used to induce pulmonary fibrosis with bleomycin. It was observed that, MCD mice were protected against bleomycin-induced lung fibrosis, but protection was diminished upon incorporation of mast cells in the lung of MCD group. Additionally, mast cell mediators such as TGF- $\beta$, histamine and renin via angiotensin (ANG) II are identified as fibrotic agents $^{[17]}$. Further, an in vitro study using both human and rat lung fibroblasts showed expression of $\mathrm{H} 1$ and AT1 receptor subtypes upon activation and they promote fibroblasts proliferation, TGF- $\beta 1$ secretion and collagen synthesis ${ }^{[18]}$. It is evident that mast cell is a major source of TNF- $\alpha$ and act as an important inflammatory marker ${ }^{[17]}$. The effects of nedocromil was investigated on rat MC-derived TNF- $\alpha$, whereby, it was reported that $2 \mathrm{~h}$ pre and $24 \mathrm{~h}$ post treatment with nedocromil inhibited TNF- $\alpha$ secretion by 20-37 and $59-83 \%$, respectively ${ }^{[63]}$. Moreover, fibroblasts and mast cells of fibrotic lungs showed presence of positive feedback effects through mast cell-derived protease enzymes, which stimulated the fibroblast growth in PAR-2/PKC-a/p44/42e dependent manner and also stimulated fibronectin and collagen production ${ }^{[36]}$.

In vivo study of sodium cromolyn against the paraquatinduced pulmonary fibrosis was carried out in rodents, where sodium cromolyn showed significant reduction in the lung tissue damage and improved lung weight. It also decreased hydroxyproline content and collagen deposition in lung almost near to control. Further, it was reported that sodium cromolyn has the potential to decrease the fibrotic effects induced by paraquat via stabilizing the mast cell and inhibition of inflammatory mediators $^{[64]}$.

\section{Phosphodiesterase (PDE) inhibitors:}

PDE inhibitors cause indirect elevation of cAMP, which inhibits fibroblast proliferation. PDE inhibition also attenuated fibroblast chemotaxis, reduced $\alpha$-SMA expression and enhanced the inhibitory effect of prostaglandin $\mathrm{E}_{2}\left(\mathrm{PGE}_{2}\right)^{[65]}$. In mice, $\mathrm{PDE}_{4}$ inhibitor, roflumilast was evaluated under both preventive (day 0-21) and therapeutic (day 11-21) study protocol, against diphtheria toxin-induced lung fibrosis and was found to 
have significantly improved the weight loss and lung collagen deposition that are the hallmarks of epithelial cell damage ${ }^{[66]}$. In bleomycin-induced lung injury model, roflumilast was reported to reduced hydroxyproline (primary pharmacodynamics marker of lung fibrosis) right ventricular hypertrophy, muscularization of pulmonary vessels and also diminished bleomycininduced transcripts for TNF- $\alpha$, TGF- $\beta$, collagen in lung tissues and growth factor. In addition, it reduced BALF containing TNF- $\alpha$, interleukin-13, TGF- $\beta$ levels and inflammatory cell counts in rats ${ }^{[67]}$.

\section{Procyanidins:}

Procyanidins are natural constituents that belong to the proanthocyanidins class, which were also known as condensed tannins. Proanthocyanidins are a class of polyphenols available in a variety of plants. Chemically, these are oligomeric flavonoids and oligomers of catechin, epicatechin and their gallic acid esters. Recently, procyanidin $\mathrm{C} 1$ type has been identified as natural antiallergic agent, which has possibility to stabilize mast cell during allergic reaction by altering the binding affinity of $\operatorname{IgE}$ with FceRI receptor ${ }^{[68]}$. In vivo study of proanthocyanidin indicated that, it could inhibit inflammatory cell infiltrations and fibrosis as well as decrease hydroxyproline content ${ }^{[69]}$.

\section{POSSIBILITY TO REVERSE ESTABLISHED IDIOPATHIC PULMONARY FIBROSIS}

There are various possible mechanisms that might be targeted to inhibit different mediators and pathways in the development of antifibrotic drugs. These may be inhibitors of cytokine, chemokine, TGF- $\beta$, tolllike receptor and antihypertensive drugs, stem cell transplantation and other strategies ${ }^{[3,4]}$. In last few decades, several potential targets and strategies were suggested for the treatment of IPF. However, challenges to the clinicians to inhibit the disease progression including reversal of established IPF are still remain the same. Moreover, it has been reported that up to $45 \%$ of all deaths pertaining to respiratory disease are somehow related usually to fibrotic disorders in developed nations ${ }^{[70]}$.

The treatment potential of antifibrotic agents in damaged tissues of lungs with no mark of histological evidence of fibrosis may be considered as an ideal treatment for $\mathrm{IPF}^{[71]}$. Also, inhibition of progression of lung fibrosis without disturbing the overall tissue healing process is primarily required in clinical management of $\mathrm{IPF}^{[72]}$. Currently, recovery from fibrosis appears unachievable even in most regenerating organ such as liver, when damaged tissue substituted with fibrous connective tissue, because persistent inflammation alters physiological changes of epithelial cell and leads to aberrant healing process ${ }^{[10,73]}$. In case of advanced IPF, degradation of ECM take place incompletely as endogenous antifibrotic mediators, MMPs are no more available in the target $\operatorname{organ}^{[74]}$. Further, up-regulation of tissue inhibitor of metalloproteinases-1 (TIMP-1) as profibrotic mediator contribute in collagen formation and inhibit ECM degradation ${ }^{[73]}$. Considering chronic inflammation as central mechanism liable for onset of $\mathrm{IPF}^{[10]}$, causes continuous mast cell activation ${ }^{[75]}$ and generates various profibrotic mediators, which leads activation and proliferation of fibroblast and enhances ECM deposition $^{[16,39]}$. This may additionally contributes in opposing the reversal of fibrotic condition and constantly disturbing the homeostasis ${ }^{[4]}$. Moreover, targets with intention to treat the fibrotic conditions are primarily concentrating to inhibit cytokines (TGF- $\beta 1)^{[76]}$, chemokines and inducers of angiogenesis, such as vascular endothelial growth factor (VEGF) $)^{[22]}$. However, many previous studies demonstrated these profibrotic mediators are primarily released from mast cell, which promoted proliferation, TGF- $\beta$ secretion and collagen synthesis by activating the fibroblasts in lung tissues. Further, clinical study data of pirfenidone and nintedanib revealed that these are preventive in long-term disease progression ${ }^{[77]}$. However, these drugs claimed to enhance life expectancy to some extent by delaying disease progression in patients but were not able to prevent continued deterioration and failure to reverse fibrotic conditions in established IPF. Hence, till now no cure is available for $\operatorname{IPF}^{[78]}$.

It is necessary to develop safe therapeutic strategies that halt disease progression and initiate reversal of established fibrosis in IPF. Overall, to obtain comprehensive recovery in established IPF, the principal prerequisites are to prevent mast cell degranulation and inhibit fibrosis simultaneously to the maximum extent. In view to enhance the therapeutic efficacy of antifibrotic agents, potentiation of antifibrotic effects with parallel augmentation of mast cell stability may be considered as a commendable approach.

An appropriate combination therapy of such antifibrotic agents, which have also an ability to impede mast cell degranulation by different mechanisms as shown in fig. 4, might advocate both retardation in disease progression and reversal of fibrotic conditions in established IPF. Because, such combination therapy 
could maximize mast cell stabilization and minimize level of profibrotic mediators. Additionally, enhancement of antifibrotic effects may synergistically inhibit collagen production and increase ECM turnover from interstitial spaces. Elevated environment of profibrotic mediators due to frequent mast cell degranulation during chronic inflammation causes fibroblasts activation, play an important role in maintaining fibrotic structures and resists in ECM degradation ${ }^{[79-83]}$, which may also effectively overcome by augmentation of mast cell stability.

Apart from these two approved drugs, pirfenidone and nintedanib, many other compounds such as adenylyl cyclase activators, $\beta$-adenoreceptor agonists, flavonoids, mast cell stabilizers, phosphodiesterase inhibitors and procyanidins have been identified. These have potential to inhibit fibrosis development as well as able to stabilize mast cell via different mechanisms. Treatment with suitable combination by using these antifibrotic agents might synergistically enhance both mast cell stability and antifibrotic effects. Therefore, such combination therapy could promise parallel potentiation of dual pharmacological effects, in retardation of disease progression as well as aid in the reversal of fibrotic condition in established IPF. Unfortunately, mainly due to lack of knowledge of benefits and risks of these combination therapies, result in loss of opportunities to enhance therapeutic control and possibility to improve patient condition in established IPF.

\section{CONCLUSION}

In conclusion, pharmacology based potentiation of mast cell stability by using different combinations of various proclaimed antifibrotic compounds reflected unique mechanistic approach in a dual manner. Firstly, it could extend the possibilities to inhibit disease progression. Secondly, these combinations might also improve quality of life by assisting the reversal of fibrotic condition of lungs, which is still challenging to the medical practitioners. Additionally, combination therapy could also lessen dose-associated adverse effects of antifibrotic agents. In future, the development of combined therapy with these compounds could effectively bring safe and novel therapeutic regimens to treat advanced stage IPF.

\section{REFERENCES}

1. Wilson MS, Wynn TA. Pulmonary fibrosis: pathogenesis, etiology and regulation. Mucosal Immunol 2009;2(2):103-21.
2. Hutchinson J, Fogarty A, Hubbard R, McKeever T. Global incidence and mortality of idiopathic pulmonary fibrosis: a systematic review. Eur Respir J 2015;46(3):795-806.

3. Fujimoto H, Kobayashi T, Azuma A. Idiopathic pulmonary fibrosis: treatment and prognosis. Clin Med Insights Circ Respir Pulm Med 2015;9(S1):179-85.

4. Raghu G, Rochwerg B, Zhang Y, Garcia CAC, Azuma A, Behr J, et al. An official ATS/ERS/JRS/ALAT clinical practice guideline: treatment of idiopathic pulmonary fibrosis. An update of the 2011 clinical practice guideline. Am J Respir Crit Care Med 2015;192(2): e3-e19.

5. Fernandez IE, Eickelberg O. New cellular and molecular mechanisms of lung injury and fibrosis in idiopathic pulmonary fibrosis. The Lancet 2012;380(9842):680-8.

6. Zaman T, Lee JS. Risk Factors for the Development of Idiopathic Pulmonary Fibrosis: a Review. Curr Pulmono Rep 2018;7(4):118-25.

7. Full prescribing information for $\mathrm{ESBRIET}^{\circledR}$.

8. Noble PW, Albera C, Bradford WZ, Costabel U, Glassberg MK, Kardatzke D, et al. Pirfenidone in patients with idiopathic pulmonary fibrosis (CAPACITY): two randomised trials. The Lancet 2011;377(9779):1760-9.

9. Wolters PJ, Collard HR, Jones KD. Pathogenesis of idiopathic pulmonary fibrosis. Annu Rev Pathol 2014;9(8):157-79.

10.Wynn TA. Cellular and molecular mechanisms of fibrosis. J Pathol 2008;214(2):199-210.

11.Chen L, Deng H, Cui H, Fang J, Zuo Z, Deng J, et al. Inflammatory responses and inflammation-associated diseases in organs. Oncotarget 2018;9(6):7204-18.

12. Moiseeva EP, Bradding P. Mast cells in lung inflammation. Adv Exp Med Biol 2011;716:235-69.

13.Amin K. The role of mast cells in allergic inflammation. Respir Med 2012;106(1):9-14.

14.Kawakami T, Galli SJ. Regulation of mast-cell and basophil function and survival by IgE. Nat Rev Immunol 2002;2(10):77386.

15.Vahid B, Dombrowski K, Awsare B. Prolonged livestock exposure and elevated serum IgE associated with pulmonary fibrosis. South Med J 2006;99(12):1408-10.

16.Erjefält JS. Mast cells in human airways: the culprit?. Eur Respir Rev 2014;23(133):299-307.

17.Veerappan A, O’Connor NJ, Brazin J, Reid AC, Jung A, McGee $\mathrm{D}$, et al. Mast cells: a pivotal role in pulmonary fibrosis. DNA Cell Biol 2013;32(4):206-18.

18.Jordana MA, Befus AD, Newhouse MT, Bienenstock J, Gauldie J. Effect of histamine on proliferation of normal human adult lung fibroblasts. Thorax 1988;43(7):552-8.

19.Moon TC, St Laurent CD, Morris KE, Marcet C, Yoshimura T, Sekar Y, et al. Advances in mast cell biology: new understanding of heterogeneity and function. Mucosal Immunol 2010;3(2):11128.

20.Eklund KK, Ghildyal N, Austen KF, Stevens RL. Induction by IL-9 and suppression by IL-3 and IL-4 of the levels of chromosome 14-derived transcripts that encode late-expressed mouse mast cell proteases. J Immunol 1993;151(8):4266-73. 
21.Cruse G, Bradding P. Mast cells in airway diseases and interstitial lung disease. Eur J Pharmacol 2016;778:125-38.

22.Chaudhary NI, Roth GJ, Hilberg F, Müller-Quernheim J, Prasse A, Zissel G, et al. Inhibition of PDGF, VEGF and FGF signalling attenuates fibrosis. Eur Respir J 2007;29(5):976-85.

23. Tomimori Y, Muto T, Saito K, Tanaka T, Maruoka H, Sumida M, et al. Involvement of mast cell chymase in bleomycin-induced pulmonary fibrosis in mice. Eur J Pharmacol 2003;478(2-3):17985.

24.Garbuzenko E, Nagler A, Pickholtz D, Gillery P, Reich R, Maquart FX, et al. Human mast cells stimulate fibroblast proliferation, collagen synthesis and lattice contraction: a direct role for mast cells in skin fibrosis. Clin Exp Allergy 2002;32(2):237-46.

25.Masuda T, Tanaka H, Komai M, Nagao K, Ishizaki M, Kajiwara $\mathrm{D}$, et al. Mast cells play a partial role in allergen-induced subepithelial fibrosis in a murine model of allergic asthma. Clin Exp Allergy 2003;33(5):705-13.

26. Taipale J, Lohi J, Saarinen J, Kovanen PT, Keski-Oja J. Human mast cell chymase and leukocyte elastase release latent transforming growth factor- $\beta 1$ from the extracellular matrix of cultured human epithelial and endothelial cells. J Biolo Chem 1995;270(9):4689-96.

27.Breton JD, Heydet D, Starrs LM, Veldre T, Ghildyal R. Molecular changes during TGF $\beta$-mediated lung fibroblast-myofibroblast differentiation: implication for glucocorticoid resistance. Physiol Rep 2018;6(7):e13669.

28. Reber LL, Frossard N. Targeting mast cells in inflammatory diseases. Pharmacol Ther 2014;142(3):416-35.

29. Siebenhaar F, Redegeld FA, Bischoff SC, Gibbs BF, Maurer M. Mast cells as drivers of disease and therapeutic targets. Trends Immunol 2018;39(2):151-62.

30.Della Latta V, Cecchettini A, Del Ry S, Morales MA. Bleomycin in the setting of lung fibrosis induction: From biological mechanisms to counteractions. Pharmacol Res 2015;97:122-30.

31.Eggli PS, Graber W. Cytochemical localization of hyaluronan in rat and human skin mast cell granules. J Invest Dermatol 1993;100(2):121-5.

32.Hügle T. Beyond allergy: the role of mast cells in fibrosis. Eur J Med Sci 2014;144:w13999.

33.Reber LL, Daubeuf F, Pejler G, Abrink M, Frossard N. Mast Cells Contribute to Bleomycin-Induced Lung Inflammation and Injury in Mice through a Chymase/Mast Cell Protease 4Dependent Mechanism. J Immunol 2014;192(4):1847-54.

34.Pesci A, Bertorelli G, Gabrielli M, Olivieri D. Mast cells in fibrotic lung disorders. Chest 1993;103(4):989-96.

35.Rankin JA, Kaliner M, Reynolds HY. Histamine levels in bronchoalveolar lavage from patients with asthma, sarcoidosis, and idiopathic pulmonary fibrosis. J Allergy Clin Immunol 1987;79(2):371-7.

36.Wygrecka M, Dahal BK, Kosanovic D, Petersen F, Taborski B, von Gerlach S, et al. Mast cells and fibroblasts work in concert to aggravate pulmonary fibrosis: role of transmembrane SCF and the PAR-2/PKC- $\alpha /$ Raf-1/p44/42 signaling pathway. Am J Pathol 2013;182(6):2094-108.

37.Inoue Y, King Jr TE, Barker E, Daniloff E, Newman LS. Basic fibroblast growth factor and its receptors in idiopathic pulmonary fibrosis and lymphangioleiomyomatosis. Am J Respir Crit Care Med 2002;166(5):765-73.

38.Fireman E, Kivity S, Shahar I, Reshef T, Mekori YA. Secretion of stem cell factor by alveolar fibroblasts in interstitial lung diseases. Immunol Lett 1999;67(3):229-36.

39.Overed-Sayer C, Rapley L, Mustelin T, Clarke DL. Are mast cells instrumental for fibrotic diseases? Front Pharmacol 2013;4(174):1-10.

40. Moiseeva EP, Roach KM, Leyland ML, Bradding P. CADM1 is a key receptor mediating human mast cell adhesion to human lung fibroblasts and airway smooth muscle cells. PloS One 2013;8(4):e61579.

41.Hetzel M, Bachem M, Anders D, Trischler G, Faehling M. Different effects of growth factors on proliferation and matrix production of normal and fibrotic human lung fibroblasts. Lung 2005; 183(4):225-37.

42.Hakim-Rad K, Metz M, Maurer M. Mast cells: makers and breakers of allergic inflammation. Curr Opin Allergy Clin Immunol 2009;9(5):427-30.

43. Galli SJ, Tsai M. IgE and mast cells in allergic disease. Nat Med 2012;18(5):693.

44.Caslin HL, Kiwanuka KN, Haque TT, Taruselli MT, MacKnight HP, Paranjape A, et al. Controlling mast cell activation and homeostasis: work influenced by Bill Paul that continues today. Front Immunol 2018;9(868):1-16.

45. Theoharides TC, Alysandratos KD, Angelidou A, Delivanis DA, Sismanopoulos N, Zhang B, et al. Mast cells and inflammation. Biochimt Biophys Acta 2012;1822(1):21-33.

46.Hong-Tao M, Beaven MA. Regulators of $\mathrm{ca}^{2+}$ signaling in mast cells potential targets for treatment of mast-cell related diseases?. Adv Exp Med Biol 2011;716:62-90.

47.Colin-York H, Li D, Korobchevskaya K, Chang VT, Betzig E, Eggeling $\mathrm{C}$, et al. Cytoskeletal actin patterns shape mast cell activation. Commun Biol 2019;2(1):93.

48.Lee SB, Kalluri R. Mechanistic connection between inflammation and fibrosis. Kidney Int 2010;78:S22-6.

49.El-Aarag B, Magdy M, AlAjmi MF, Khalifa SA, El-Seedi HR. Melittin exerts beneficial effects on paraquat-induced lung injuries in mice by modifying oxidative stress and apoptosis. Molecules 2019;24(8):1498.

50.Seamon KB, Padgett W, Daly JW. Forskolin: unique diterpene activator of adenylate cyclase in membranes and in intact cells. Proc Natl Acad Sci U S A 1981;78(6):3363-67.

51.Liu X, Sun SQ, Ostrom RS. Fibrotic lung fibroblasts show blunted inhibition by cAMP due to deficient cAMP response element-binding protein phosphorylation. J Pharmacol Exp Ther 2005;315(2):678-87.

52.Lambers C, Boehm PM, Karabacak Y, Samaha E, Benazzo A, Jaksch $\mathrm{P}$, et al. Combined activation of guanylate cyclase and cyclic AMP in lung fibroblasts as a novel therapeutic concept for lung fibrosis. Bio Med Research Int 2019;2019:1-10.

53. Satish L, Gallo PH, Baratz ME, Johnson S, Kathju S. Reversal of TGF- $\beta 1$ stimulation of $\alpha$-smooth muscle actin and extracellular matrix components by cyclic AMP in Dupuytren's-derived 
fibroblasts. BMC Musculoskelet Disord 2011;12(1):113.

54.Liu X, Ostrom RS, Insel PA. cAMP elevating agents and adenylyl cyclase overexpression promote an antifibrotic phenotype in pulmonary fibroblasts. Am J Physiol Cell Physiol 2004;286(5):C1089-C99.

55.Goulet S, Bihl MP, Gambazzi F, Tamm M, Roth M. Opposite effect of corticosteroids and long-acting $\beta 2$-agonists on serumand TGF- $\beta 1$-induced extracellular matrix deposition by primary human lung fibroblasts. J Cell Physiol 2007;210(1):167-76.

56.Silvestri M, Fregonese L, Sabatini F, Dasic G, Rossi GA. Fluticasone and salmeterol downregulate in vitro, fibroblast proliferation and ICAM-1 or H-CAM expression. Eur Respir J 2001;18(1):139-45.

57.Spoelstra FM, Postma DS, Hovenga H, Noordhoek JA, Kauffman HF. Budesonide and formoterol inhibit ICAM-1 and VCAM-1 expression of human lung fibroblasts. Eur Respir J 2000;15(1):68-74.

58.Baouz S, Giron-Michel J, Azzarone B, Giuliani M, Cagnoni F, Olsson S, et al. Lung myofibroblasts as targets of salmeterol and fluticasone propionate: inhibition of alpha-SMA and NF-kB. Int Immunol 2005;17(11):1473-81.

59. Wei QF, Wang XH, Zhang XY, Song LJ, Wang YM, Wang Q, et al. Therapeutic effects of quercetin on bleomycin induced pulmonary fibrosis in rats. Int J Clin Exp Med 2016;9(2):516167.

60.Hohmann MS, Habiel DM, Coelho AL, Verri Jr WA, Hogaboam CM. Quercetin enhances ligand-induced apoptosis in senescent idiopathic pulmonary fibrosis fibroblasts and reduces lung fibrosis in vivo. Am J Resp Cell Mol 2019;60(1):28-40.

61.Kilic T, Ciftci O, Cetin A, Kahraman H. Preventive effect of chrysin on bleomycin-induced lung fibrosis in rats. Inflammation 2014;37(6):2116-24.

62.Chen CY, Peng WH, Wu LC, Wu CC, Hsu SL. Luteolin ameliorates experimental lung fibrosis both in vivo and in vitro: implications for therapy of lung fibrosis. J Agric Food Chem 2010;58(22):11653-61.

63. Bissonnette EY, Enciso JA, Befus AD. Inhibition of tumour necrosis factor-alpha (TNF- $\alpha$ ) release from mast cells by the anti-inflammatory drugs, sodium cromoglycate and nedocromil sodium. Clin Exp Immunol 1995;102(1):78-84.

64.Hemmati AA, Nazari Z, Motlagh ME, Goldasteh S. The role of sodium cromolyn in treatment of paraquat-induced pulmonary fibrosis in rat. Pharmacol Res 2002;46(3):229-34.

65.Racké K, Haag S, Bahulayan A, Warnken M. Pulmonary fibroblasts, an emerging target for anti-obstructive drugs. Naunyn Schmiedebergs Arch Pharmacol 2008;378(2):193-201.

66.Sisson TH, Christensen PJ, Muraki Y, Dils AJ, Chibucos L, Subbotina N, et al. Phosphodiesterase 4 inhibition reduces lung fibrosis following targeted type II alveolar epithelial cell injury. Physiol Rep 2018;6(12):e13753.
67.Cortijo J, Iranzo A, Milara X, Mata M, Cerda-Nicolas M, RuizSauri A, et al. Roflumilast, a phosphodiesterase 4 inhibitor, alleviates bleomycin-induced lung injury. $\mathrm{Br} \mathrm{J}$ Pharmacol 2009;156(3):534-44.

68.Basu A, Sarkar A, Basak P. Immunoinformatics study of procyanidins as mast cell stabilizers. Pharmacogn J 2018;10(4):814-17.

69.Agackiran Y, Gul H, Gunay E, Akyurek N, Memis L, Gunay S, et al. The efficiency of proanthocyanidin in an experimental pulmonary fibrosis model: comparison with taurine. Inflammation 2012;35(4):1402-10.

70.Rosenbloom J, Mendoza FA, Jimenez SA. Strategies for antifibrotic therapies. Biochim Biophys Acta 2013;1832(7):10881103.

71.Razzaque MS, Taguchi T. Pulmonary fibrosis: cellular and molecular events. Pathol Int 2003;53(3):133-45.

72.Sgalla G, Iovene B, Calvello M, Ori M, Varone F, Richeldi L. Idiopathic pulmonary fibrosis: pathogenesis and management. Resp Res 2018;19(1):32.

73.Tanaka M, Miyajima A. Liver regeneration and fibrosis after inflammation. Inflamm Regen 2016;36(1):1-6.

74.Issa R, Zhou X, Constandinou CM, Fallowfield J, MillwardSadler H, Gaca MD. Spontaneous recovery from micronodular cirrhosis: evidence for incomplete resolution associated with matrix cross-linking. Gastroenterology 2004;126(7):1795-1808.

75.Metz M, Grimbaldeston MA, Nakae S, Piliponsky AM, Tsai M, Galli SJ. Mast cells in the promotion and limitation of chronic inflammation. Immunol Rev 2007;217(1):304-28.

76.Iredale JP. Models of liver fibrosis: exploring the dynamic nature of inflammation and repair in a solid organ. J Clin Invest 2007;117(3):539-48.

77.Zurkova M, Kriegova E, Kolek V, Lostakova V, Sterclova M, Bartos $\mathrm{V}$, et al. Effect of pirfenidone on lung function decline and survival: 5-yr experience from a real-life IPF cohort from the Czech EMPIRE registry. Resp Res 2019;20(1):16.

78.Somogyi V, Chaudhuri N, Torrisi SE, Kahn N, Müller V, Kreuter M. The therapy of idiopathic pulmonary fibrosis: what is next?. Eur Respir Rev 2019;28(153).

79.Kendall RT, Feghali-Bostwick CA. Fibroblasts in fibrosis: novel roles and mediators. Front Pharmacol 2014;5:123.

80.Usher KM, Zhu S, Mavropalias G, Carrino JA, Zhao J, Xu J. Pathological mechanisms and therapeutic outlooks for arthrofibrosis. Bone Res 2019;7(1):1-24.

81.Giannandrea M, Parks WC. Diverse functions of matrix metalloproteinases during fibrosis. Dis Model Mech 2014;7(2):193-203.

82.Lawrance IC, Rogler G, Bamias G, Breynaert C, Florholmen J, Pellino G, et al. Cellular and molecular mediators of intestinal fibrosis. J Crohns Colitis 2017;11(12):1491-503.

83.Beghdadi W, Madjene LC, Claver J, Pejler G, Beaudoin L, Lehuen A, et al. Mast cell chymase protects against renal fibrosis in murine unilateral ureteral obstruction. Kidney Int 2013;84(2):317-26. 